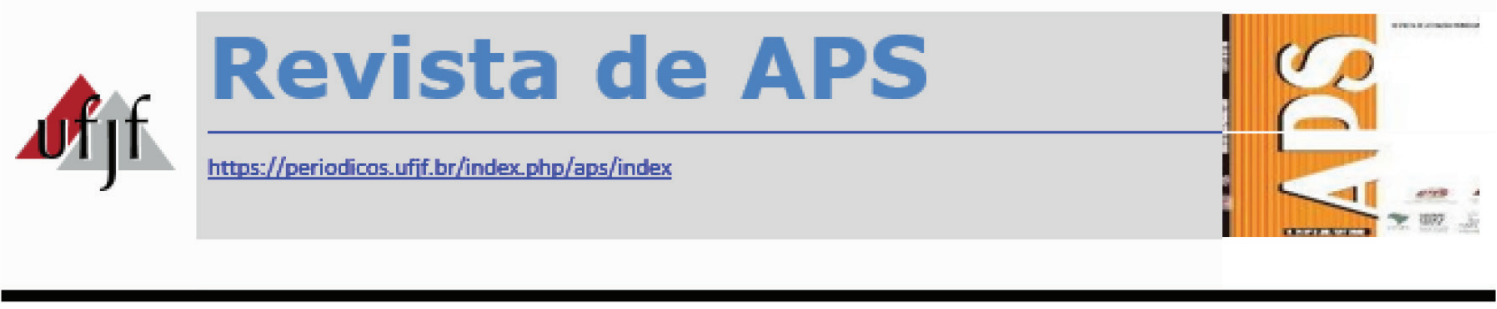

\title{
Ampliação da clínica de saúde bucal em um centro de saúde do município de Campinas a partir de uma perspectiva grupal
}

\author{
The buccal health clinic expansion on a public system family health \\ located in Campinas city by group's perspective
}

\author{
Angela Andrade Martins ${ }^{1}$, Núncio Antônio Araújo Sól² ${ }^{2}$ Carlos Botazzo ${ }^{3}$, Luciane \\ Maria Pezzato ${ }^{4}$
}

\section{RESUMO}

A inserção da equipe de Saúde Bucal na Estratégia Saúde da Família teve como proposta provocar mudanças no modo de organizar a produção do cuidado hegemonicamente ofertada pelos serviços de saúde da atenção primária no Sistema Único de Saúde, no Brasil. O objetivo deste trabalho foi analisar, a partir de um grupo educativo com hipertensos e diabéticos de uma equipe de saúde da família do município de Campinas-SP, possibilidades de ampliação da clínica da Saúde Bucal. A promoção da saúde foi pano de fundo dessa pesquisa, pois entendemos que as práticas grupais são dispositivos importantes para a ampliação da clínica na atenção primária à saúde. O referencial teóricometodológico foi da Análise Institucional em sua abordagem sócio-histórica e utilizamos como ferramentas para a produção dos dados: análise de documentos arquivados que traziam registros sobre o grupo, entrevistas com profissionais e usuários/as integrantes do grupo, um grupo focal com a equipe de saúde da família do qual este grupo faz parte e a produção de um diário de pesquisa. Trinta sujeitos participaram desta pesquisa, sendo 15 nas entrevistas e 15 no grupo focal. A partir da análise dos dados produzidos, foi possível perceber o potencial deste grupo como um dispositivo para ampliação da clínica de Saúde Bucal. O fato de a dentista estar inserida no grupo como parte integrante do mesmo foi um diferencial que fez a equipe de saúde rever o lugar da Saúde

\footnotetext{
${ }^{1}$ Secretaria Municipal de Saúde de Campinas. Universidade Estadual de Campinas. E-mail: angelandrad@uol.com.br

${ }^{2}$ Universidade Federal de Ouro Preto.

${ }^{3}$ Faculdade de Saúde Pública-USP.

${ }^{4}$ Universidade Federal de São Paulo - Campus Baixada Santista.
} 
Bucal na produção do cuidado, consequentemente na promoção da saúde.

PALAVRAS-CHAVE: Saúde Bucal. Saúde Coletiva. Promoção da Saúde. Atenção Primária à Saúde. Grupos.

\section{ABSTRACT}

The insertion of the Buccal Health team in the Family Health Strategy had as its proposition to provoke changes in the organization of the production of care hegemonically offered by Primary Health Attention's services in the Unified Health System (SUS), in Brazil. The goal of this paper is to analyze - from the perspective of an educational group with hypertensive and/or diabetic patients located in the work area covered by family health team in the public system, in Campinas (São Paulo) city - the possibilities of an expansion in the buccal health clinic. The Health Promotion was the foundation of this research, as we understand that groups are an important tool in the Primary Health Attention work towards the expansion of the clinic. The theoretical-methodological contribution came from Institutional Analysis in its socio-historical approach and we used as tools to produce the data: the analyses of pre-existent documents which contained entries concerning the group; interviews performed with professionals and members of the group; a focus group with the referred family health team and also the production of a research journal. Thirty subjects participated in this research- half in the interviews and half in the focus group. From the analyses of the produced data, it was possible to perceive the potential held by this group as a tool for the buccal health clinic expansion. The insertion of the dentist in the group as one of its active members was the key-factor which caused the health team to reevaluate the Buccal Health's place in the production of care, and, consequently, in Health Promotion.

KEYWORDS: Buccal Health. Public Health. Health Promotion. Primary Health Attention. Groups.

\section{INTRODUÇÃO}

A Declaração de Alma-Ata formulada na Conferência Mundial sobre Cuidados Primários de Saúde, em setembro de 1978, veio a se tornar um marco importante para o desenvolvimento da Atenção Primária à Saúde (APS), proposta como núcleo central de um sistema de saúde ${ }^{1}$. Foi um dos mais importantes documentos de saúde em escala mundial e mantém sua atualidade ainda hoje. Segundo Ayres ${ }^{2}$, foram recomendados oito itens para as políticas de saúde: educação, prevenção e controle dos problemas de saúde; promoção do suprimento de alimentos e nutrição adequada; água e saneamento básico adequados; atenção maternoinfantil e planejamento familiar; imunização; prevenção e controle das doenças endêmicas; tratamento apropriado de doenças comuns e acidentes; e distribuição de medicamentos básicos.

Um dos desdobramentos de Alma-Ata foram as Conferências Internacionais e Mundiais sobre a Promoção da Saúde que continuam acontecendo, até os dias atuais, gerando "documentos de referência resultantes do processo de discussão e construção 
coletiva sobre os conceitos fundamentais abordados no contexto da Promoção da Saúde, realizado em várias partes do mundo"3.

De acordo com Ayres $^{2}$, essas conferências levaram a uma mudança de paradigma na prevenção e promoção da saúde, resultando em sete princípios: concepção holística da saúde; intersetorialidade; empoderamento; participação social; equidade; ações multiestratégicas; e sustentabilidade.

No Brasil, o Ministério da Saúde ${ }^{4: 8}$ (MS) reconceituou APS como Atenção Básica, com o seguinte enunciado:

Um conjunto de ações de saúde, no âmbito individual ou coletivo, que abrange a promoção e proteção da saúde, a prevenção de agravos, o diagnóstico, o tratamento, a reabilitação e a manutenção da saúde situadas no primeiro nível de atenção dos sistemas de saúde.

Na perspectiva de reorganizar a APS, o MS criou, em 1994, o Programa da Saúde da Família (PSF), que em 2006 passou a ser reconhecido como uma Estratégia, através da Portaria 648/2006 do $\mathrm{MS}^{5}$, passando assim a se denominar Estratégia Saúde da Família (ESF).

Houve uma grande mobilização em nível nacional para a implantação desse novo modo de organizar as ações de saúde, uma vez que junto dele havia um repasse de recursos por programa e equipes implantados. Ocorreram muitos debates sobre modelos políticos e técnicos do trabalho em saúde, sendo que Campinas-SP adotou, em 2001, o modelo Paidéia-Saúde da Família. Tal modelo possuía algumas modificações na proposta original, sendo a principal delas de trabalhar com uma equipe ampliada, incorporando o médico pediatra e o médico ginecologista, trabalhando na lógica da clínica ampliada.

Quando Campos 6:63-4 propõe trabalhar com a clínica ampliada, está trazendo uma mudança de paradigma no pensar e fazer saúde, com um olhar mais amplo, para uma clínica do sujeito, sendo uma aposta para:

[...] superar a alienação e a fragmentação e o tecnicismo biologicista, centrando-se no eixo da reconstituição de Vínculos entre Clínico de Referência e sua clientela. Superar a fragmentação entre a biologia, subjetividade e sociabilidade operando-se com Projetos Terapêuticos amplos, que explicitem objetivos e técnicas da ação profissional e que reconheçam um papel ativo para o ex-paciente, para o enfermo em luta e em defesa de sua saúde [...]

Acreditamos na potência da clínica ampliada no cotidiano do trabalho em saúde na APS e entendemos que as ações de Promoção da Saúde (PS) fazem parte desta clínica, uma vez que ela traz em seus pressupostos a construção de se estabelecer vínculo entre profissional e usuário.

Na Promoção da Saúde, as práticas grupais são dispositivos importantes, como nos lembra Costa ${ }^{7: 469}$ :

[...] na promoção da saúde, o trabalho em grupos possibilita a quebra da relação vertical que, tradicionalmente, existe entre 
o profissional da saúde e o sujeito da sua ação, sendo esta uma estratégia facilitadora da expressão das necessidades, expectativas, angústias e circunstâncias de vida que têm algum impacto na saúde de indivíduos e de grupos.

O trabalho com grupos é uma prática presente em diferentes profissões da área da saúde, apresentando referenciais teóricos dos mais variados. No limite deste artigo, não pretendemos aqui esgotar essa discussão. Tomamos as práticas grupais como dispositivos. De acordo com Barros ${ }^{8: 75}$, Lourau e Lapassade, integrantes do movimento institucionalista francês, na década de 50 criticaram o grupalismo, rompendo com o instituído das dinâmicas de grupo efetuada pelos socioanalistas. A autora vai nos dizer que, desde então, o grupo "não mais será olhado/utilizado como algo-em-si, mas como dispositivo criado, que põe algo em funcionamento [...]. A denúncia empreendida pelos socioanalistas nos possibilitou resgatar o aspecto não natural do grupo".

Nesse sentido, o trabalho com dispositivo grupal vai ao encontro da perspectiva da ESF, que busca desnaturalizar o enfoque biomédico, trazendo para a cena o trabalho interdisciplinar e multiprofissional, a inter-relação entre os sujeitos usuários dos serviços, possibilitando a circulação de saberes e novas experiências. Com isso, apresenta outros modos de fazer a clínica, colocando o sujeito como protagonista e corresponsável na produção do seu cuidado, assim como percebem que não estão sozinhos nas suas condições de saúde, que existem mais pessoas que compartilham dos mesmos problemas de saúde e de adoecer, entendidos como "formas pelas quais a vida se manifesta. Correspondem a experiências singulares e subjetivas, impossíveis de serem reconhecidas e significadas integralmente pela palavra" 9:42.

Porém, trabalhar em equipe é um grande desafio, pois nem sempre os profissionais de saúde se colocam disponíveis para (com)partilhar conhecimentos e saberes, como ficou evidenciado na Política Nacional de Saúde Bucal-PNSB ${ }^{4: 18}$ :

Embora constituindo a equipe de trabalho de uma Unidade Básica de Saúde, esses profissionais nem sempre estão preparados e com disposição para agir de forma integrada. Saber lidar com esses encontros é um enorme desafio, pois além do potencial de integração, é também um lugar de conflitos, de resistências e de disputas.

Nisso tudo existe uma questão importante que remete às características da formação em saúde, em que o saber científico médico centrado dominou por muito tempo esse processo, formando profissionais voltados para uma assistência individual, curativista, tecnicista, denominado Modelo Biomédico.

Com a Odontologia, esse processo não foi diferente. Para compor com nossa discussão, trazemos as tecnologias propostas por Merhy ${ }^{10}$, que nos auxiliam a pensar na organização tecnológica do trabalho na Odontologia. Há uma notável predominância das tecnologias duras e leve-duras na clínica odontológica. Reiteramos a necessidade das mesmas para produzir o cuidado e restabelecer a saúde bucal do usuário, pois é preciso 
conhecimento técnico (tecnologia leve-dura) e também a utilização de equipamentos, aparelhos, instrumentos (tecnologia dura). Porém, estes sozinhos não são o suficiente para alcançar o cuidado integral do indivíduo. Para tal, são fundamentais as tecnologias relacionais (tecnologias leves). Como relatam Franco e Merhy 11:155: "A integralidade pode se realizar como uma diretriz burocrática e meramente prescritiva, quando sobretudo os processos de sua realização ficam centrados nos procedimentos, no ato burocrático, nas maquinarias, instrumentos". Assim, entendemos que são as pactuações que se estabelecem no encontro entre os profissionais e os usuários que poderão produzir outras formas de cuidado pautadas, também, nas tecnologias leves ${ }^{12}$.

É nesse sentido que apostamos na ampliação da clínica da Saúde Bucal, temática amplamente discutida no desenvolvimento do Projeto "Inovação na produção do cuidado em Saúde Bucal: Possibilidades de uma nova abordagem na clínica odontológica para o Sistema Único de Saúde"13, que propôs novas tecnologias para o cuidado em Saúde Bucal na APS, tendo sido realizado em 2013/2014. Em Campinas, o Projeto Inovação desenvolveu-se em dois Centros de Saúde, sendo um deles o Centro de Saúde no qual realizamos esta pesquisa. Foi quando muitos questionamentos vieram à tona, tais como: Quais usuários estão tendo acesso às ações de Saúde Bucal? Será que apenas o atendimento na cadeira odontológica seria resolutivo ou deveríamos investir mais na Promoção da Saúde e, em outros espaços, acessando mais usuários? Será que a clínica da Saúde Bucal só acontece na cadeira odontológica?

Por conseguinte, finalizada aquela pesquisa, a primeira autora deste artigo deu início em 2016 a uma pesquisa de Mestrado Profissional em Saúde Coletiva: Políticas e Gestão em Saúde da FCM-Unicamp, com intuito de responder a algumas daquelas questões. Defendemos a ideia de que a Saúde Bucal pode ampliar sua clínica não só nos espaços historicamente consagrados do consultório odontológico e nos procedimentos preventivos coletivos realizados nas escolas. Pode e deve também ocupar outros espaços juntamente com os demais profissionais das equipes de saúde, como nas visitas domiciliares, nos conselhos de saúde, nas reuniões de equipe, nas ações de vigilância, na integração ensino-serviço-comunidade, nos espaços de gestão, nas ações de promoção da saúde, dando destaque aos grupos educativos, abrindo assim o leque de opções para o profissional ampliar também sua visão enquanto trabalhador de uma unidade básica de saúde que oferece diferentes serviços para a produção do cuidado.

Encontramos na literatura estudos que trazem a emergência de uma abordagem ampliada para a clínica da saúde bucal ${ }^{12 ; 14 ; 15 ; 16 ; 17}$.

Estamos entendendo Saúde Bucal como um campo de saberes e práticas que não é o mesmo da Odontologia. Saúde Bucal pode ser entendida como um movimento instituinte dentro da Odontologia. "Por 'instituinte' entendemos, ao mesmo tempo, a contestação, a capacidade de inovação e, em geral, a prática política como 'significante' da prática social”18:47. A Saúde Bucal traz uma abordagem da clínica ampliada à clínica 
odontológica tradicional, instituída, centrada nos dentes e em suas exclusivas técnicas de reparo. ${ }^{18 ; 19 ~ " O ~ " i n s t i t u i ́ d o " ~ n a ̃ o ~ s o ́ ~ s e ~ c o l o c a ~ c o m o ~ a ~ o r d e m ~ e s t a b e l e c i d a, ~ o s ~ v a l o r e s, ~}$ como também modos de representação e de organização considerados normais, como igualmente os procedimentos habituais de previsão (econômica, social e política)"19:47.

Uma vez que para Cunha 20:34 "a clínica ampliada seria capaz de lidar com a singularidade de cada sujeito sem abrir mão da ontologia das doenças e suas possibilidades", ou seja, entende que é necessário tratar a doença, mas também é importante ater-se às forças internas e externas que afetam o sujeito doente, tendo assim um olhar biológico, psicológico e social. Para trabalhar sobre a ótica da Clínica Ampliada, faz-se necessário trabalhar a autonomia do sujeito, quanto mais ele se conhecer, entender sobre a sua condição de saúde, souber o que ele pode fazer para melhorar, ou o que se fizer piora sua condição, mais será corresponsável pelo seu cuidado.

Por isso, entendemos que é preciso ir além, e compreender o adoecimento bucal para além da boca, além dos dentes, enfim, olhar para o sujeito que adoece, pois a boca faz parte de um corpo, corpo este que pulsa, vive, sonha, sofre, exercitando toda sua bucalidade. De acordo com Botazzo 21:81: "Bucalidade vem sendo entendida como a capacidade da boca em ser boca, isto é, em exercer sem limitação ou deficiência as funções para as quais anatomicamente acha-se apta." O autor continua:

Não é difícil perceber o quanto essas três dimensões se acham ligadas à cultura e ao psiquismo. São, ao mesmo tempo, produtos sociais e, por isso, dotados de historicidade, quer dizer, a boca humana é socialmente produzida e seus produtos - manducação, erótica e linguagem - são igualmente produtos sociais. Por isso, se pode dizer que a boca não é órgão, mas território, e assim o suporte mais evidente de todo o corpo do homem na realização da sua vida.

Para tanto, é fundamental nesse processo enxergar o outro, escutar suas demandas, respeitar suas necessidades, permitindo um diálogo com o paciente, estabelecendo um vínculo, tornando-o corresponsável pelo seu processo saúde-doença-cuidado.

O objetivo deste trabalho foi analisar, a partir de um grupo educativo com hipertensos e diabéticos de uma equipe de saúde da família do município de CampinasSP, possibilidades de ampliação da clínica da Saúde Bucal.

Este grupo educativo de hipertensos e diabéticos existe desde 2002, com ações semanais interdisciplinares contando, também, com a participação de estudantes de graduação da PUC-Campinas dos cursos de Enfermagem, Medicina, Nutrição e Odontologia.

\section{Percurso teórico-metodológico}

Trata-se de uma pesquisa qualitativa, onde foi utilizado o referencial teóricometodológico da Análise Institucional (AI) em sua vertente Sócio-histórica, "por 
possibilitar compreender também situações passadas"22:183 no grupo e não apenas como o grupo se encontra hoje.

A Análise Institucional Sócio-histórica é justificada por Savoye ${ }^{23}$ no sentido de que para se entender a institucionalização é necessário ter uma referência à sua história, compreendida em história recente ou antiga, que pode ser em um campo restrito, como em um estabelecimento, por exemplo. Institucionalização é o terceiro momento do conceito de instituição, designa um "processo que se desdobra no tempo e só é perfeitamente compreensível mediante a reconstituição de seu desenvolvimento diacrônico. A ideia de institucionalização, portanto, implica raciocinar em termos de duração, temporalidade e historicidade"24:181.

Apoiados nos estudos de René Lourau ${ }^{25}$, a instituição é um movimento dinâmico e dialético, resultado de três momentos: o instituído, o instituinte e a institucionalização.

O momento do instituído, do que está posto, estabelecido, ou seja, as normas, as leis, o que o autor chamou de universal. O momento do instituinte, que, por seu turno, exprime a particularidade, a negação do instituído, do universal [...]. O resultado da relação entre estes dois momentos - instituído e instituinte - é a institucionalização, o momento da singularidade ${ }^{25: 390}$.

O centro de saúde, local onde foi realizada esta pesquisa, é uma unidade de saúde da família que está inserida na Política de Integração Ensino-Serviço-Comunidade do município, sendo cenário de práticas de diversos cursos da área da saúde da Pontifícia Universidade Católica de Campinas. Possui uma população adscrita de 21.597 habitantes (fonte: Sistema de Informação Tab Net-SMS de Campinas) e está organizada com três equipes de referência de saúde da família, sendo que a equipe envolvida nesta pesquisa tem uma característica marcante de apresentar um grande número de idosos.

Como ferramenta para produção dos dados, utilizamos o Diário de Pesquisa (DP) que foi construído pela dentista-pesquisadora durante todo o percurso desta pesquisa em seu cotidiano do serviço. Segundo Pezzato e L'Abbate 26:1302:

O diário de pesquisa seria a narrativa do pesquisador em seu contexto histórico-social, um pesquisador implicado com e na pesquisa, e que reflete sobre e com a sua atividade de diarista. Trata-se de uma técnica capaz de restituir, na linguagem escrita, o trabalho de campo.

Com o intuito de atingir nossos objetivos, foram utilizadas algumas técnicas da pesquisa qualitativa, além do DP, como: análise documental, entrevista e grupo focal.

Assim que obtivemos aprovação do Comitê de Ética em 20 de maio de 2016, iniciamos nosso trabalho de campo com uma entrevista da profissional que foi uma das fundadoras do referido grupo, realizada na própria Unidade de Saúde.

Após a realização da entrevista com a profissional, demos sequência para o segundo momento: as entrevistas com usuários/as que frequentavam o grupo há mais de cinco anos, que eram assíduos e participavam ativamente nos encontros do grupo. As 
entrevistas foram realizadas no mesmo local onde acontece o grupo, com 15 usuários/ as. Todas as entrevistas foram realizadas pela dentista-pesquisadora e foram utilizados pseudônimos, escolhidos pelos próprios participantes para preservar o anonimato, tanto nas entrevistas como no grupo focal.

Com o intuito de ampliar nosso entendimento sobre a institucionalização do grupo, realizamos um grupo focal com os profissionais que pertencem à equipe de saúde do qual o grupo faz parte, trazendo assim outros elementos para reflexão e discussão aos dados produzidos na pesquisa. O grupo focal foi realizado no dia da reunião de equipe, convidamos os 20 profissionais que a compõem. Porém, 15 estiveram presentes no dia agendado. Seguindo a técnica do grupo focal, a moderadora foi uma pessoa que não participou da pesquisa, mas que tinha experiência com grupos focais, e a pesquisadora ficou como observadora do processo. Esta pesquisa seguiu todos os preceitos da Resolução 466/12 do CNS referentes aos aspectos éticos. Teve a aprovação do Comitê de Ética em Pesquisa da Unicamp - campus Campinas - CEP UNICAMP, processo no 1.552.954. Todos os sujeitos que aceitaram participar da pesquisa assinaram o Termo de Consentimento Livre e Esclarecido (TCLE) e sua identidade foi preservada, usandose de pseudônimos para denominá-los. A coleta de dados foi realizada no período de 25/05/2016 a 02/03/2017.

\section{O grupo, suas histórias e uma dentista-pesquisadora implicada: analisando os dados}

Implicação é um dos conceitos fundamentais na Análise Institucional.

Para Lourau ${ }^{25: 36}$, implicados todos estamos, pois não é uma questão de vontade, mas sim de como nos relacionamos com as diferentes instituições que nos atravessam. Na Análise Institucional trata-se de análise de implicações, que "é o cerne do trabalho socioanalítico, e não consiste somente em analisar os outros, mas em analisar a si mesmo a todo momento, inclusive no momento da própria intervenção."

A análise da implicação para Savoye 27:147 "supõe interrogar igualmente as condições sociais, políticas e institucionais que geram uma pesquisa, as modalidades concretas segundo as quais se efetua, assim como o alcance científico e prático de seus resultados."

No contexto desta pesquisa, evidenciamos a veracidade do exposto por Savoye ${ }^{23: 189}$ de que

[...] o trabalho histórico pode ter efeitos analisadores do presente e pode inclusive engendrar, se forem reunidas circunstâncias para tanto através de dispositivos grupais que permitam uma palavra coletiva, verdadeiros momentos socioanalíticos. De uma maneira geral, uma viva implicação está em funcionamento no trabalho histórico e nada proíbe os autores de se apoderar dela, trazendo-a à luz e tentando analisá-la. 
Trata-se de um processo difícil, ou mesmo impossível, retratar com neutralidade a história de um grupo do qual você faz parte. A imparcialidade desafia o aspecto humano existente em nós; ao contrário, a dentista-pesquisadora se encontrou envolvida o tempo todo com o grupo de hipertensos e diabéticos, como cita em seu diário:

Continuo fazendo a transcrição da entrevista [da Profissional] e fico pensando como eu estou implicada com o grupo, e até mesmo sobre implicada, pois eu torço, vibro e às vezes falo junto com ela, interrompendo o seu relato (Diário de Pesquisa, 02/06/2016).

Para resgatar a história do grupo, a dentista-pesquisadora teve dificuldade em encontrar dados documentais, deparando-se com a falta de registros nas atas; o que encontrou foram apenas pastas com nome dos participantes, número da ficha familiar e data dos encontros.

Nessas anotações, localizou também registro da contagem da hipertensão arterial sistêmica (HAS) e da diabetes mellitus (DM), número de consultas agendadas e renovação de receitas médicas. Alguns usuários/as tinham o nome destacado com caneta marcadora de texto com uma observação, por exemplo: "marcar consulta com ginecologia", "marcar acuidade visual", "fazer receita", informações desse tipo.

A análise documental concluiu que esses registros trazem indícios da relação presente entre os profissionais de saúde com os/as integrantes do grupo numa perspectiva biomédica, demonstrando, assim, o quanto essa racionalidade está instituída no modelo de atenção, direcionando a organização do trabalho em saúde presente nas atividades educativas da atenção básica. Prova disso é que não foram registradas outras atividades no livro ata. Como a dentista-pesquisadora fazia parte deste centro de saúde desde o início das atividades do grupo, foi possível resgatar da memória outros trabalhos realizados, como palestras com diferentes temas e inserções de profissionais de várias áreas da saúde, mesmo que em atividades pontuais. Utilizando-se desse conhecimento, a dentista-pesquisadora buscou registros adicionais com profissionais/usuários participantes do grupo tais como fotos, gravações e vídeos das atividades que mostravam momentos festivos, comemorações de datas especiais, realização de bingos, exposição de trabalhos manuais feitos pelas senhoras frequentadoras do grupo, ilustrando e comprovando a existência dessas outras atividades. Entendemos que essas atividades podem não ter importância clínica para alguns profissionais, como se não fizessem parte do tratamento ou da clínica, algo "menor", que não está em nenhum protocolo ou descrito nos procedimentos técnicos dos profissionais de saúde.

Existe uma grande dificuldade para os/as profissionais da saúde entenderem que a clínica está presente em nossas práticas cotidianas nos serviços, não necessariamente relacionada puramente ao núcleo da prática profissional, conforme proposto por Campos $^{28: 220}$, quando afirma que 
A institucionalização dos saberes e sua organização em práticas se daria mediante a conformação de núcleos e de campos. [...] 0 núcleo demarcaria a identidade de uma área de saber e de prática profissional; e o campo, um espaço de limites imprecisos onde cada disciplina e profissão buscariam em outras apoio para cumprir suas tarefas teóricas e práticas.

Assim, quando saímos desse espaço nuclear, "idealizado" por uns, e produzimos práticas clínicas do campo profissional, como a que foi realizada nesta pesquisa, com inserção em práticas com grupos, podemos provocar questionamentos se essas práticas também fazem parte da clínica. Na Saúde Bucal tal situação está fortemente presente.

Conforme enfatiza Fajardo ${ }^{29}$, há uma questão cultural, envolvendo os sujeitos com relação ao processo operacional do dentista, em que ainda pesa o velho e tradicional lugar nuclear, instituído: a cadeira odontológica.

A cultura tradicional enfatiza a imagem do dentista em um consultório com instrumentos na mão, realizando procedimentos e cercado de um aparato tecnológico. Creio que neste ponto deve ser feita uma reflexão sobre a identidade e o papel de uma odontóloga como trabalhadora comunitária em uma equipe multidisciplinar que entrecruza seus conhecimentos e práticas. [...] O que reforçou o incômodo da dentistapesquisadora colocando em dúvida se realmente ela continuaria sendo dentista se não estivesse no gabinete, cercada de instrumentos e "arrancando" um dente! ?9:139-141 $^{2}$

No grupo focal houve uma discussão referente ao conceito de campo e núcleo, reforçando o fato de que a dentista pode/consegue ter práticas que saem do núcleo:

[...] me chama muito atenção quando a pesquisadora, enquanto dentista sai do núcleo. Porque principalmente o profissional dentista não tem tanto isso na formação né, da coisa da Saúde Coletiva, da coisa do grupo, então fica mais pessoal, se a pessoa gosta, se a pessoa tem esse desejo né. Então me chama muito atenção a pesquisadora consegue sair do núcleo dela né da odonto, dentista, que tem uma rotina que te deixa dentro de sala. Achei muito interessante isso, do dentista conseguir participar. A gente deveria proporcionar mais isso, quando a gente pensa grupo, a gente quer enfermagem e médico eu acho também muito ruim por que se a enfermeira não vai, se auxiliar não vai, não quer ir ou não pode mais é muito mais o nosso núcleo e a gente tem pouca oportunidade para isso e aí quando os outros profissionais saem do núcleo eu acho enriquece muito mais, quando ela consegue sair do núcleo ( Blanques - Grupo Focal).

Diante disto, percebemos a necessidade de uma discussão maior sobre qual clínica queremos e podemos produzir no cotidiano de trabalho em Saúde Bucal na APS e, especificamente, nos grupos, local onde ela também é efetivada. A ampliação da clínica da Saúde Bucal permite um olhar para além dos dentes, procurando entender melhor a situação em que o sujeito se encontra, quais são suas condições sistêmicas, psíquicas e sociais e o quanto isso reverbera na sua condição bucal. Em contrapartida, o profissional médico necessita também enxergar o paciente como um todo, ou seja, com boca e corpo. Botazzo ${ }^{30}$ alertava 
para esta questão: "O saber médico não penetra nas condições bucais, que desse modo se mantém como 'coisa de dentista'."

Se pausarmos aqui para refletir, concluiremos segundo Zimerman"31:27: "todo indivíduo passa a maior parte do tempo de sua vida convivendo e interagindo com distintos grupos". Ou seja, família, escola, grupos profissionais, esportivos e sociais. Portanto, a origem de grupos na vida do indivíduo se faz presente desde o seu nascimento. Historicamente, segundo Zimerman ${ }^{31: 23}$, Pratt em 1905, em uma enfermaria com pacientes tuberculosos, orientava os mesmos com cuidados de higiene e, portanto: "pode-se dizer que esta se constituiu na primeira experiência grupoterápica registrada na literatura especializada".

Encontramos na literatura estudos que trazem a temática de Grupos com diferentes abordagens teórico-metodológicas 7;32;33;34;35;36;37;3. Não é proposta deste artigo problematizar tais abordagens, mas dizer como se deu o trabalho com o grupo de hipertensos e diabéticos de uma equipe de saúde da família em questão.

Tal grupo foi formado em 2002 para atender a uma política do governo federal chamada Hiperdia, onde seria feito um cadastro dos pacientes hipertensos e diabéticos, relatando suas medicações. Participaram dessa concepção do grupo quatro profissionais: uma médica generalista (Doutora), duas agentes comunitárias de saúde (ACS-fundadora e Lucila) e uma enfermeira (Enfermeira). No início o grupo era realizado no próprio centro de saúde, porém, como a demanda crescia a cada semana, foi transferido para outro local, a antiga sede social do bairro pertencente ao território da equipe de saúde da família.

\section{Conhecer a percepção dos usuários e dos profissionais sobre o grupo}

As entrevistas com os usuários do grupo foram um momento especial, pois enriqueceram e contribuíram muito para entender melhor o próprio grupo:

Tenho feito as transcrições das entrevistas com os usuários, e é interessante, pois cada um traz uma parte, o seu ponto de vista, sua necessidade e vão se unindo numa grande colcha de retalhos. E, nesse frio que está fazendo, percebo que esta colcha aquece, agasalha e acolhe a todos. Sem dúvida, é mais que um grupo educativo: eles buscam convívio social, amizade, melhora para a depressão, etc. (Diário de Pesquisa, 13/06/2016).

Nas entrevistas, os usuários demonstraram muita afinidade pelo grupo, compromisso, pois frequentam o grupo há mais de cinco anos, e todos afirmaram terem aprendido muito no modo de lidar com as doenças, mas enfatizaram também o momento do encontro entre eles, de interação com as outras pessoas como eles, que vivem questões de saúde-doença semelhantes em suas vidas, conforme podemos constatar nos relatos de alguns usuários durante as entrevistas:

Ah eu gosto assim porque eu vejo pessoas, porque eu não saio, fico dentro de casa, né! Só saio para vir aqui e domingo à noite na igreja, mas eu conheci muita gente 
aqui converso com pessoas, assim da minha idade ou mesmo um pouco mais nova, então e aí eu me sinto bem (Entrevista com usuário-1, 08/06/2016).

Ah! eu gostei muito das ginásticas, né, porque eu sou meio 'paradona', então para mim foi bom fazer ginástica aqui, foi bom ouvir as palestras eu aprendi muito com as palestras sobre o diabetes né, a gente tira as nossas dúvidas para mim foi bom demais porque eu vivo perguntando né (Entrevista com usuário-2, 8/06/2016).

O grupo proporcionava empoderamento aos seus frequentadores, deixando claro que era um espaço democrático, feito para e com eles, garantindo a centralidade do sujeito.

A gente deu essa liberdade para eles, entendeu? Deles agirem porque o grupo, o grupo é nosso! Assim como eu [Lucila] e a ACS-fundadora falamos: - Vocês têm o mesmo direito'. E a gente tinha muita roda de conversa então isso deu autonomia, levantou a auto-estima, você entendeu?! Quando eles não gostavam, eles interrompiam e falavam: - Olha está acontecendo isso assim, assim acho que é bom a gente conversar entendeu, aconteceu não sei o quê com fulano. Eles tinham autonomia" (Entrevista com Lucila, 25/05/2016).

Outro fato relevante é que o grupo se realizava num local pertencente ao território da equipe de saúde do qual os frequentadores fazem parte, facilitando o seu acesso, como pudemos observar na entrevista com um dos usuários:

É... mais próximo nossa! Se a gente tem que andar longe, é uma dificuldade, e eu falo assim: quando a gente é mais jovem é diferente o negócio, agora eu já vejo as dificuldades pra sair... até que eu vou lá pra aquele fundão, mas eu tenho medo de ir sozinha, às vezes não tem quem me leva, porque eu só tenho filho homem e eles trabalham né! Então fica difícil pra mim estar indo longe (Entrevista com usuário-1, 08/06/2016).

Importante ressaltar aqui a questão da necessidade de articular gestão e clínica para o êxito de qualquer atividade. O grupo tem um potencial grande na Atenção Primária à Saúde, fato que deve ser ressaltado dentro e fora das equipes, assim como para a gestão, os profissionais da assistência, os usuários, pois o grupo na promoção da saúde é também uma extensão da clínica. Com um olhar a longo prazo, a Promoção da Saúde busca resultados longitudinais e tão importantes quanto os procedimentos da clínica biomédica. Na organização da clínica deve haver espaço para prevenção, promoção, proteção e recuperação.

Diante disso, vemos uma necessidade de negociar com a gestão, formas de as atividades grupais terem relevância na produtividade, somente assim conseguiremos discutir os nós encontrados no exercer da clínica rotineiramente em uma Unidade Básica de Saúde, que é um lócus muito complexo de se trabalhar.

Além da gestão do nível central, é preciso negociar também com a gestão no nível local. Por exemplo, disputas/problemas com recursos humanos podem afetar a manutenção do grupo. 
Falei assim: - Não vai mais ninguém? Não vai um auxiliar de enfermagem? Não vai um enfermeiro? Teve a crise na época. E aí nós tínhamos uma enfermeira que falou assim: - Ah, mas não tem funcionário, por mim tudo bem, se não tiver funcionário, por mim pode até acabar o grupo... A gente teve... Ela não está mais aqui, foi uma das coisas... Um dos embates que eu participei disso (Corintiano - Grupo Focal).

Através dos anos, o grupo com hipertensos e diabéticos passou por momentos de crises e a enfermagem por vezes relutou em disponibilizar a ACS-fundadora para participar do grupo, alegando que com a falta de pessoal seria mais útil que ela entrasse na escala de enfermagem e que seria até melhor que o grupo deixasse de existir. Em conversas paralelas, a ACS-fundadora desabafou, contando que teve que lutar muito para que esse grupo fosse mantido.

E conseguimos fazer com muito, com jogo de cintura, porque você sabe que o sistema não capacita o suficiente para fazer grupos, você tem que buscar. Eu [Lucila] graças à Deus, aliás a população teve uma parceria muito boa com a Doutora, a Enfermeira, a ACS-fundadora e eu (Entrevista com Lucila, 25/05/2016).

$\mathrm{Na}$ fala anterior de Lucila, notamos a necessidade da Educação Permanente em Saúde (EPS) para melhorar a formação do profissional trabalhador da saúde, questão importante que deve estar em pauta nos planejamentos da gestão. A EPS é um investimento necessário dentro de um serviço público, ainda mais por se trabalhar numa equipe multiprofissional. Machado et al. ${ }^{39: 337}$ reforçam:

Para que seja possível a realização de uma prática que atenda à integralidade, precisamos exercitar efetivamente o trabalho em equipe, desde o processo de formação do profissional de saúde. É preciso estabelecer estratégias de aprendizagem que favoreçam o diálogo, a troca, a transdisciplinaridade entre os distintos saberes formais e nãoformais que contribuam para as ações de promoção de saúde a nível individual e coletivo.

O trabalho realizado com grupos possibilita essa proximidade entre o trabalhador da saúde e o usuário e um fator relevante seria a disponibilidade de tempo, para não só se poder escutar com mais tranquilidade, como também dialogar num espaço de maior proximidade, de troca, possibilitando trazer para o debate a corresponsabilização pelo cuidado. Campos ${ }^{40: 685}$ ressalta que se "há uma dimensão produtora de autonomia para a clínica, é aquela em que - por meio do vínculo pode-se desenhar um campo de propostas terapêuticas que recoloquem o sujeito no trilho da responsabilização pela própria vida".

[...] já no grupo você sai do ambiente, da relação médico-paciente, apesar de ser o médico e o paciente, então mudando o ambiente a pessoa parece que fica mais desarmada, e o médico também, ele fica mais desarmado. Então fica assim uma relação mais horizontalizada (Turco - Grupo Focal).

Como não poderia deixar de ser, muitas coisas "veladas" começaram a aparecer na discussão. Por exemplo, a questão do poder, ou melhor, da disputa pelo poder, de repente todos queriam ser o dono do grupo. De forma geral, o efeito do analisador é 
sempre de revelar algo que permanecia escondido, de desorganizar o que estava de certa forma organizado, de dar um sentido diferente a fatos já conhecidos:

Um grupo que a gente lutou tanto para manter. Foi bom porque a gente aprendeu, eu aprendi muito, mas nós tínhamos perdido o empoderamento (Lucila - Grupo Focal).

[...] A professora falou: quem é essa mulher que está sentada na cadeira? Porque digamos assim eu tinha um certo domínio sobre... para o grupo, não domínio, um... uma liberdade, por assim dizer (Lucila - Grupo Focal).

[...] lembrando que são diferentes as idades de quem vai no Progen e no grupo de hipertensos e diabéticos, são grupos diferentes, de dinâmicas diferentes. 0 "meu" é um grupo mais calado, vamos dizer assim, eles integram sim entre nós, mas eles são mais reservados do que o pessoal que vem para cá do Progen, que é mais dinâmico é um grupo menor ele se expressa mais. São mais jovens do que os "meus" pacientes de lá, os nossos pacientes, aliás (Corintiano - Grupo Focal)

[...] Porque é assim às vezes a gente ouve assim: - Mas é do centro de saúde o grupo, não é da PUC! Não é tal, não é dos agentes, não é da ACS-fundadora, tá, mas a gente às vezes gostaríamos de ver uma participação maior também de outras pessoas (Corintiano - Grupo Focal).

Houve até uma discussão entre Corintiano e Lucila, na qual ele estava tentando explicar o motivo pelo qual várias pessoas (usuários e profissionais) declaravam que o grupo era da ACS-fundadora:

- Mas a gente tem que ver que é a humanidade dela [ACS-fundadora]. Acho que talvez é por isso... o carisma dela [ACS-fundadora] que era muito grande... Lucila! Que às vezes a gente... A pessoa falava: - $O$ grupo da ACS-fundadora. Acho que é por isso... pela maneira dela. Entendo quando você fala... (Corintiano - Grupo Focal).

- Não, não, o povo lá fora eu acho ótimo, mas o povo aqui dentro não (Lucila Grupo Focal).

Desde o início do grupo, principalmente com a saída da médica (Doutora), houve essa disputa pelo poder entre as duas Agentes Comunitárias de Saúde. Como a ACSfundadora foi a escolhida, Lucila decidiu sair do grupo naquele momento:

- Porque a gente aprende que a saúde ela não é feita só de medicação, você entendeu, ela é feita de várias formas, a gente vai usando vários artifícios, várias atividades. Como eu participo de mais 3 grupos, esse eu saí, eu abandonei, não tô mais a fim, eu fico assim onde eu me sinto... (Lucila - Grupo Focal)

- À vontade? (Moderador - Grupo Focal)

- Não à vontade não. Útil. (Lucila - Grupo Focal)

- Útil! (Moderador - Grupo Focal)

- Quando eu vejo eu não sou mais útil, eu saio, porque feliz a gente só fica na praia (Lucila - Grupo Focal). 
Essa disputa pelo poder é inerente ao processo de institucionalização, considerando-se a existência de uma "institucionalização fundadora (IF), processo pelo qual a instituição toma forma, ao mesmo tempo em que cria as condições para sua perpetuação" e de uma institucionalização ordinária (ou permanente) 24:185.

No município de Campinas, a implantação da estratégia Saúde da Família iniciou em 2001, tendo em sua maioria equipes de saúde bucal modalidade 1 (dentista e auxiliar de saúde bucal) nas Unidades de Saúde. O grupo de Hipertensos e Diabéticos foi fundado no Centro de Saúde que participa desta pesquisa em 2002, mas somente em 2012 a dentista-pesquisadora começou a participar, incorporandose ao grupo semanalmente. Com o passar do tempo, todos/as (usuários/as e membros da equipe) viam com naturalidade esse fato, sendo um marco importante na sua trajetória profissional.

Durante a busca sobre a história do grupo, um fato nos pareceu relevante: a participação dos/as profissionais da Odontologia da Unidade era mínima, restrita apenas a palestras pontuais e, mais importante ainda, sem se ater ao fato de o/a profissional fazer ou não parte da equipe de referência, observando-se apenas a disponibilidade de um profissional dentista naquele momento. Isso reforça entendimento equivocado da equipe de saúde sobre o campo da Saúde Bucal, como se os/as profissionais da equipe de saúde bucal não fizessem parte da equipe de referência. Em contrapartida, não houve um movimento de interesse da Saúde Bucal para mudar essa situação, como se concordassem e deixassem assim seguir, fechando-se no seu núcleo.

Dentre os princípios norteadores da ESF, estão a centralidade na pessoa/ família e o vínculo com usuário. Certamente o grupo possibilitou a existência dos mesmos, pois nas atividades desenvolvidas no grupo há mais tempo disponível para estar com os usuários do que em uma consulta, existe possibilidade de falar sobre temas variados, de estabelecer proximidade entre os participantes, potencializando uma ampliação da clínica.

[...] Ele quer chegar num lugar e ser tratado com respeito, que tenha resposta medicamentosa, que seja um ambiente saudável, agradável, que ele faça amizade, possa confiar, parece muita coisa, mas não é, tudo isso esse grupo acabou proporcionando, pessoas que moravam há 20 anos no bairro, não se olhavam, foram se conhecer no grupo, então a gente aprende não só a ser valorizado lá fora, porque aqui dentro a gente não é. Mas também eles se sentem valorizados, porque nós fomos até eles (Lucila - Grupo Focal).

Com o trabalho de campo foi possível perceber que as atividades grupais têm grande potencial de ampliação da clínica da Saúde Bucal, como podemos constatar nas falas a seguir:

[...] E essa participação, a confiança que eles têm nela, né, que sabe a referência: Olha, eu posso procurar a [Dentista-pesquisadora] porque ela é minha referência, ela vai entender como eu sou, tanto dentro do consultório quanto no grupo. E isso é importante (Didi - Grupo Focal). 
[...] ele vem, ele traz o neto, daí ele traz o filho né [risos], é legal, é muito legal. Só que não passa com o outro, tem que passar com a dentista-pesquisadora (Angélica - Grupo Focal).

O grupo hoje continua acontecendo, tem alguns momentos de alta e baixa, o que é pertinente aos processos grupais. Em 2017 ele completou 15 anos de existência e de sustentabilidade, ou seja, continua forte e vivo.

Para um grupo existir e resistir desde 2002, deve haver um significado, buscar saúde é um motivo razoável, mas encontrar amigos, espaço para conviver, para conversar, rir, brincar, declamar poesia... Isso sim justifica a sustentabilidade de um grupo. Isso também é promover saúde.

\section{CONSIDERAÇÕES FINAIS}

Diante de todo o processo desta pesquisa, uma questão fundamental foi compreender que o trabalho com grupos é clínica, seja ela da Bucal ou de qualquer outra clínica que compõe o cotidiano das práticas profissionais de saúde. Podemos perceber como o grupo de hipertensos e diabéticos proporcionou uma forte ligação entre a dentista-pesquisadora e os/as usuários/as integrantes do grupo, aumentando o vínculo e a confiança. Possibilitou a ampliação do acesso para o tratamento odontológico na cadeira para muitos integrantes, estendendo para outros membros da família, como filhos/as e netos/as e rompendo com alguns estigmas do medo que muitos idosos/as possuíam. Porém, não foi possível inserir essa temática na pauta de discussões com os demais membros da equipe de saúde bucal da Unidade.

Evidenciou, no e com o grupo, que o/a profissional da saúde bucal pode e deve ocupar diferentes espaços de atuação não se restringindo ao núcleo de saberes e práticas que a odontologia ocupa historicamente. $O$ fato de a dentista estar presente semanalmente no grupo, fazendo parte do mesmo, fez a equipe de saúde perceber que este é também um espaço para um profissional da Saúde Bucal atuar.

Defendemos a posição de que todo profissional deveria ter espaço em sua agenda para participar de práticas grupais, pois trabalhos com grupos não são exclusividades dos/as agentes comunitários/as de saúde, dos/as técnicos/as de enfermagem, dos/as enfermeiros/as. O grupo é um dispositivo democrático, com espaço para profissionais com formações distintas, seja de nível técnico ou de nível universitário, pois trata-se de uma prática importante para, inclusive, atingir melhoras das condições de saúde, em médio e longo prazo, que é nosso objetivo maior no SUS.

O conceito de Bucalidade contribuiu para o entendimento das reais demandas dos sujeitos, uma vez que analisamos os territórios bucais e, com a fala liberada, participamos das atividades grupais, pesquisamos e estudamos cada situação encontrada no individual 
e coletivo, foi possível integrar o que foi visto, escutado e vivido para produzir saúde em sua integralidade.

Acreditamos que os bons resultados citados anteriormente devem estimular novas pesquisas neste campo, visando não só comparar resultados como também, e talvez principalmente, possibilitar a discussão da ampliação dos modos de se fazer clínica nas unidades de saúde, estimulando a multiprofissionalidade e a interdisciplinaridade.

\section{AGRADECIMENTOS}

Agradecemos aos integrantes do grupo de hipertensos e diabéticos e aos profissionais da equipe de referência pela participação e contribuições para a viabilidade deste trabalho.

\section{REFERÊNCIAS}

1. Arantes JL, Shimizu HE, Hamann EM. Contribuições e desafios da Estratégia Saúde da Família na Atenção Primária à Saúde no Brasil: revisão da literatura. Ciên Saúde Coletiva. 2016; 21(5):1499-1509.

2. Ayres JRCM. Prevenção de agravos, promoção da saúde e redução de vulnerabilidade. In: Martins MA, et al. Clínica Médica-Medicina-USP-HC. São Paulo: Manole; 2009. p. 437-55.

3. Ministério da Saúde (Brasil). As cartas de promoção à saúde. Brasília: Ministério da Saúde; 2002.

4. Ministério da Saúde (Brasil). Secretaria de Atenção Básica. Departamento de Atenção Básica. Cadernos de Atenção Básica. Brasília, Ministério da saúde. 2008; 17:8-18.

5. Ministério da Saúde (Brasil). Portaria 648 de 28 de março de 2006. Diário Oficial da União. Brasília, DF, 2006 mar 28.

6. Campos GWS. A clínica do sujeito: por uma clínica reformulada e ampliada. In.: Campos GWS. Saúde Paidéia. São Paulo: Hucitec; 2003. p. 51-67.

7. Costa RC, Rodrigues CRF. Percepção dos usuários acerca das práticas de promoção da saúde, vivenciadas em grupos, em uma unidade básica de saúde da família. Rev APS. 2010 out-dez; 13(4):465-75.

8. Barros RB. Institucionalismo e dispositivo grupal. In.: Rodrigues HBC, Altoé S, organizadores. Saúdeloucura número 8. Análise institucional. São Paulo: Hucitec; 2004. p. 65-78.

9. Czeresnia D. O conceito de saúde e a diferença entre prevenção e promoção. In.: Czeresnia D, Freitas CM, organizadores. Promoção da Saúde: conceitos, reflexões, tendências. Rio de Janeiro: Editora Fiocruz; 2003. p. 39-53. 
10. Merhy EE. Saúde: Cartografias do Trabalho Vivo. São Paulo: Hucitec; 2002.

11. Franco TB, Merhy EE. Cartografias do Trabalho e Cuidado em Saúde. Tempus Actas Saúde Coletiva. 2012; 6(2):151-63.

12. Pezzato LM, L'abbate $S$, Botazzo C. Produção de micropolíticas no processo de trabalho em saúde bucal: uma abordagem socioanalítica. Ciên Saúde Coletiva. Rio de Janeiro. 2013; 18(7):2095-2104.

13. Botazzo C, et al. Inovação na produção do cuidado em saúde bucal. Possibilidades de uma nova abordagem na clínica odontológica para o Sistema Único de Saúde. Relatório Técnico. São Paulo: Fapesp; 2015.

14. Bortoli FR, Kovaleski DF, Moretti-Pires RO. Medicalização social e bucalidade: a busca pela superação da técnica. Cad. Saúde Coletiva. No prelo 2019. Disponível em: http://www.scielo.br/scielo.php?script=sci_arttext\&pid=S1414-462X201900500110 $5 \& \operatorname{lng}=$ en $\&$ nrm=iso \&tlng=pt.

15. Fonseca GS, et al. Redesenhando caminhos na direção da clínica ampliada de saúde bucal. Saúde soc. [on line]. 2018; 27(4):1174-85.

16. Fonsêca, Graciela Soares et al. A clínica do corpo sem boca. Saude soc. 2016 dez; 25(4):1039-49.

17. Barros RS, Botazzo C. Subjetividade e clínica na atenção básica: narrativas, histórias de vida e realidade social. Ciênc. saúde coletiva. 2011 nov; 16(11):4337-48.

18. Lourau R. O Instituinte contra o instituído. In: Altoé $S$, organizador. René Lourau: Analista institucional em tempo integral. São Paulo: Hucitec; 2004. p. 47-65.

19. Botazzo C. Da arte dentária. São Paulo: Hucitec, FAPESP; 2000.

20. Cunha GT. A construção da clínica ampliada na atenção básica [dissertação]. Campinas (SP): Faculdade de Ciências Médicas Universidade Estadual de Campinas; 2004. $182 f$.

21. Botazzo C. A bucalidade no contexto da Estratégia Saúde da Família: ajudando a promover saúde para indivíduos, grupos e famílias. In: Moysés ST, Kriger L, Moysés SJ. Saúde bucal das famílias. Trabalhando evidências. São Paulo: Artes Médicas Divisão Odontológica; 2008. p. 81-8.

22. Sól NAA. Medicina geral comunitária no Brasil: uma análise institucional sóciohistórica da sua trajetória. In: L'abbate S, Mourão LC, Pezzato LM, organizadores. Análise Institucional \& Saúde Coletiva. São Paulo: Hucitec; 2013. p. 180-205.

23. Savoye A. Análise institucional e pesquisas sócio-históricas: estado atual e novas perspectivas. Mnemosine. 2007; 3(2)181-93.

24. Lourau R. Análise Institucional. 1ạ ed. Petrópolis: Vozes; 1975. 294 p. 
25. Lourau R. René Lourau na UERJ: análise institucional e práticas de pesquisa. Rio de Janeiro: Ed. UERJ; 1993.

26. Pezzato LM, L'abbate S. O uso de diários como ferramenta de intervenção da Análise Institucional: potencializando reflexões no cotidiano da Saúde Bucal Coletiva. Physis Rev Saúde Coletiva. 2011; 21(4):1297-1314.

27. Savoye A. Analyse Institutionnnelle et recherche sócio-historiques: quele compatibilité? L'Homme et la Société. 2003; 147(8):133-50.

28. Campos GWS. Saúde pública e saúde coletiva: campo e núcleo de saberes e práticas. Ciênc Saúde Colet. 2000; 5(2):219-30.

29. Fajardo AP. Onde está a dentista? In: Mano MAM, Prado EV, organizadores. Vivências de educação popular na atenção primária à saúde: a realidade e a utopia. São Carlos: EdUFSCar; 2010. p. 129-45.

30. Botazzo C. Bucalidade. Pro Odonto Prevenção. 2013; 6(4):9-55.

31. Zimerman DE. Fundamentos Teóricos. In: Zimerman DE, et al. Como trabalhamos com grupos. Porto Alegre: Artes Médicas; 1997. p.23-31.

32. Oliveira NL. Práticas educativas e integralidade na saúde da família. Um estudo etnográfico. [dissertação]. Natal (RN): Universidade Federal Rio Grande do Norte; 2013.

33. Fernandes MTO, et al. Utilização de tecnologias no trabalho com grupos de diabéticos e hipertensos na Saúde da Família. Ciênc Saúde Colet. 2011; 16 Supl: 1331-40.

34. Gomes TJO, Silva MVR, Santos AA. Controle da pressão arterial em pacientes atendidos pelo programa Hiperdia em uma Unidade de Saúde da Família. Rev Bras Hipertens. 2010; 17(3):132-9.

35. Afonso MLM. Oficinas em Dinâmica de grupo: um método de intervenção psicossocial. In: Afonso MLM. Oficinas em Dinâmica de grupo: um método de intervenção psicossocial. São Paulo: Casa do Psicólogo; 2006. p. 9-61.

36. Tavares CMA, Matos E, Gonçalves L. Grupo multiprofissional de atendimento ao diabético: uma perspectiva de atenção interdisciplinar à saúde. Texto Contexto Enferm. 2005 abr-jun; 14(2):213-21.

37. Maffacciolli R, Lopes MJM. Educação em saúde: a orientação alimentar através de atividades de grupo. Acta Paul Enferm. 2005; 18(4):439-45.

38. Barros RB. Dispositivos em ação: o grupo. In: Silva A. Cadernos de Subjetividade. São Paulo: Hucitec; 1997; 6:183-91.

39. Machado MFAS, Monteiro EMLM, Queiroz DT, Vieira NFC, Barroso MGT. Integralidade, formação de saúde, educação em saúde e as propostas do SUS: uma revisão conceitual. Ciênc Saúde Colet. 2007; 12(2):335-42. 
40. Campos RTO, Campos GWS. Co-construção de autonomia: o sujeito em questão. In: Campos GWS, et al, organizadores. Tratado de Saúde Coletiva. São Paulo: Hucitec; 2006. p. 669-87.

Submissão: novembro de 2018. Aprovação: maio de 2019. 